\title{
Wind Force Coefficients for Designing Porous Canopy
}

\section{Roofs}

\author{
Yasushi Uematsu $^{1}$, Hiromichi Sakurai ${ }^{2}$, Yukari Miyamoto ${ }^{3}$ and Eri Gavansky ${ }^{1}$ \\ 1. Department of Architecture and Building Science, Graduate School of Engineering, Tohoku University, Sendai 980-8579, Japan \\ 2. Tohoku Electric Power Co., Inc., Sendai 980-8550, Japan \\ 3. Kume Sekkei Co. Ltd., Tokyo 135-8567, Japan
}

\begin{abstract}
Wind force coefficients for designing porous canopy roofs have been investigated based on a series of wind tunnel experiments. Gable, troughed and mono-sloped roofs were tested. The roof models were made of $0.5 \mathrm{~mm}$ thick perforated duralumin plates, the porosity of which was changed from 0 to about 0.4 . Overall aerodynamic forces and moments acting on the roof model were measured in a turbulent boundary layer with a six-component force balance for various wind directions. The results indicate that the wind loads on canopy roofs generally decrease with an increase in porosity of the roof. Assuming that the roof is rigid and supported by the four corner columns with no walls, the axial forces induced in the columns are regarded as the most important load effect for discussing the design wind loads. Two loading patterns causing the maximum tension and compression in the columns are considered. Based on a combination of the lift and moment coefficients, the design wind force coefficients on the windward and leeward halves of the roof are presented for the two loading patterns as a function of the roof pitch and porosity. The effect of porosity is taken into account as a reduction factor of the wind loads.
\end{abstract}

Key words: Canopy roof, porosity, wind force coefficient, wind tunnel experiment, codification.

\section{Introduction}

Porous canopy roofs are often used for providing shade in public spaces, e.g., sports grounds, playgrounds, shopping areas and parking lots, particularly in Australasian and Middle Eastern countries. Shade cloth fabrics are generally used for such roofs. Whereas some extensive researches into the wind loads on solid canopy roofs have been made (e.g., Gumley [1], Letchford and Ginger [2], Ginger and Letchford [3] and Uematsu et al. [4, 5]), there is very little information on the wind loads on porous canopy roofs. Letchford et al. [6] measured the mean wind forces on porous canopy roofs, i.e., hip, gable and mono-sloped roofs with roof pitches from 7 to $27^{\circ}$ in a turbulent boundary layer. The roof models were made of perforated plates with a range of porosity from 0 to

Corresponding author: Yasushi Uematsu, professor, research fields: architectural wind engineering (wind effects on buildings and structures, wind environment, wind power generation etc.). E-mail yu@archi.tohoku.ac.jp.
0.23 . They investigated the effect of porosity on the mean wind forces. Mean and fluctuating pressures along the center line of the roof were also measured. However, the dynamic load effect of turbulence on the roof structures was not discussed in detail.

The present paper discusses the design wind force coefficients on porous canopy roofs, based on a series of wind tunnel experiments with rigid models made of thin perforated plates for three geometries, i.e., gable, troughed and mono-sloped roofs. The basic idea for specifying the wind force coefficients is the same as that the authors used for the solid canopy roofs [4]. The effect of porosity of the roof is taken into account as a reduction factor of the wind force coefficients.

It should be mentioned that the present paper is a revised version of the previous one [7].

\section{Pressure Loss Coefficients}

Porosity was deemed the dominant dimensionless parameter for the first stage of the present study. The 
porosity $p$ of the material is defined as the ratio of the open area to the total enclosed area, and the solidity is defined as $1-p$. Porosity is difficult to define for shade cloth fabrics. The cover factor often used for the classification of shade cloth fabrics may be equivalent to solidity. However, the porosity or solidity is not the only parameter that governs the aerodynamics of porous materials. Wind forces acting on porous structures will depend not only on the porosity but also on the shape of the "pores or holes" making up the porous material. For example, sharp-edged holes will have different characteristics to woven fibers. An alternative to porosity is the pressure loss coefficient defined as:

$$
K=\frac{P_{u}-P_{d}}{\rho \bar{U}^{2} / 2}
$$

where, $P_{u}$ and $P_{d}$ are respectively the upstream and downstream static pressures on either side of the material, $\rho$ is the air density, and $\bar{U}$ is the average approach velocity. The pressure loss coefficient is a measure of the resistance to flow through a porous material and includes the effects of porosity as well as shape of "holes". Thus, similarity of wind loading will be best achieved by equality of pressure loss coefficient between fabrics and perforated plates to be used for wind tunnel models [6]. Here, the pressure loss characteristics of a range of shade cloth fabrics will be compared with those measured for various thin perforated metal plates of known porosity, or the diameter and spacing of circular holes.

The pressure loss measurements are performed in a small wind tunnel of $125 \mathrm{~mm}$ diameter, in which the entire cross-section is covered by various materials being tested. The specimens are made of $0.5 \mathrm{~mm}$ thick duralumin plates and the porosity is provided by drilling a number of small circular holes into the plate. The diameter $d$ and spacing $s$ of the holes are changed as shown in Table 1 , to provide a porosity range from 0.10 to 0.53 . Specimens 5 to 8 have the same porosity of 0.30 with different combinations of $d$ and $s$. The values of $K$ for these specimens are almost the same.
This feature implies that the pressure loss coefficient is not affected by $d$ (or $s$ ) significantly. It is mainly affected by $p$ within the limits of the present experiment.

Fig. 1 shows the pressure loss coefficient $K$ plotted against the porosity $p$ for the perforated plates. The value of $K$ decreases significantly with an increase in $p$ up to about 0.3 , beyond which the variation is relatively small. Similar results were obtained by Aihara and Terazaki [8] for plates with small rectangular holes. The relation between $K$ and $p$ is approximately given by the following equation (solid line in Fig. 1):

$$
K=0.52 p^{-2.6}
$$

Measurements were also made for four kinds of shade cloth fabrics labeled as $\mathrm{A}$ to $\mathrm{D}$ that are commonly used in practical design. The values of $K$

Table 1 Test specimens (perforated plates).

\begin{tabular}{lllll}
\hline No. & $d(\mathrm{~mm})$ & $s(\mathrm{~mm})$ & $p$ & $K$ \\
\hline 1 & 1.0 & 2.8 & 0.10 & 167.4 \\
2 & 0.95 & 2.0 & 0.18 & 43.26 \\
3 & 0.95 & 1.8 & 0.22 & 24.17 \\
4 & 1.15 & 2.0 & 0.26 & 20.70 \\
5 & 1.4 & 2.27 & 0.30 & 12.12 \\
6 & 1.6 & 2.59 & 0.30 & 12.04 \\
7 & 1.8 & 2.91 & 0.30 & 11.60 \\
8 & 2.0 & 3.24 & 0.30 & 12.53 \\
9 & 0.95 & 1.5 & 0.32 & 11.28 \\
10 & 0.95 & 1.4 & 0.36 & 6.515 \\
11 & 1.64 & 2.0 & 0.53 & 2.074 \\
\hline
\end{tabular}

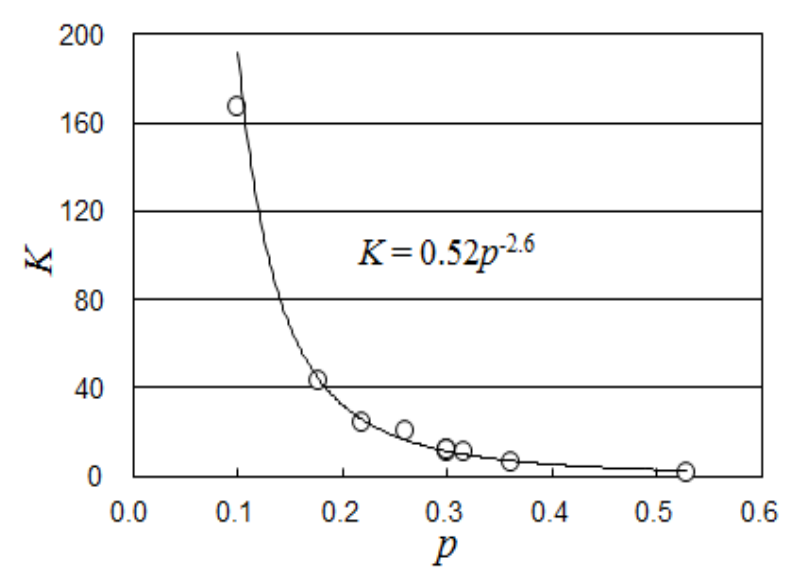

Fig. 1 Variation of pressure loss coefficient $K$ with porosity $p$. 
for these fabrics are summarized in Table 2, together with the other characteristics. The values of $K$ are within the range of the perforated plates tested in the present study.

\section{Wind Tunnel Experiments with Rigid Porous Roof Models}

\subsection{Roof Models}

Fig. 2 shows the wind tunnel models tested in the experiments. Three types of roof geometry, i.e., gable, troughed and mono-sloped roofs are tested. The models are made of perforated duralumin plates of $150 \mathrm{~mm}$ square and $0.5 \mathrm{~mm}$ thickness. Two values of $p$ (i.e., 0.20 and 0.36 ) are tested, considering the values of $K$ for practical shade cloth fabrics shown in Table 2 together with the relation between $K$ and $p$ given by Eq. (2). A solid model $(p=0)$ is also tested. The roof pitch $\beta$ is varied from 0 to $20^{\circ}$. The roof is supported by four aluminum legs of $6 \mathrm{~mm}$ diameter. The mean roof height $H$ is $80 \mathrm{~mm}$. The length scale $\lambda_{L}$ of the models is assumed 1/100.

\subsection{Measurements with a Force Balance}

The aerodynamic forces and moments acting on a roof model is measured by a six-component force balance (SSK, LBW60-1) in a turbulent boundary layer with a power law exponent of $\alpha=0.20$, which simulates natural wind over typical suburban exposure. The notation and coordinate system used in the present study are shown in Fig. 3. The lift $L$ and the

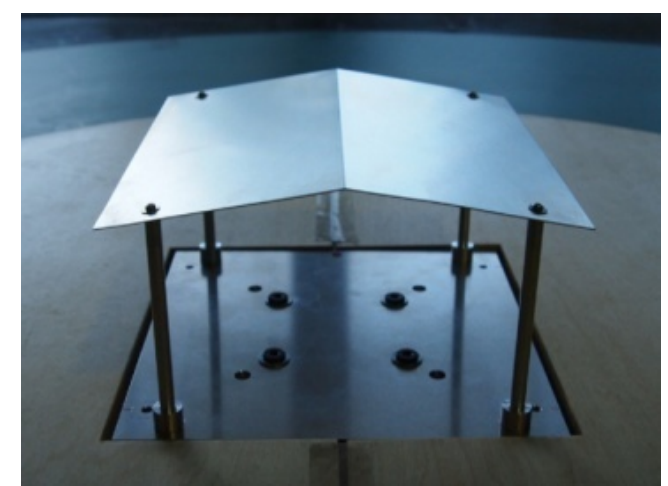

(a) Gable roof aerodynamic moments $M_{x}$ and $M_{y}$ about the $x$ and $y$ axes are normalized as follows:

$$
C_{L}=\frac{L}{q_{H}(b l)}, \quad C_{M x}=\frac{M_{x}}{q_{H}\left(b l^{2}\right)}, C_{M y}=\frac{M_{y}}{q_{H}\left(b^{* 2} l\right)}
$$

where, $q_{H}=$ velocity pressure at the mean roof height $H$, and $b^{*}=$ actual length of the roof $(=b / \cos \beta)$.

The wind velocity $U_{H}$ at the mean roof height $H$ is 9 $\mathrm{m} / \mathrm{s}$. The corresponding Reynolds number $R e$, defined in terms of $U_{H}$ and $H$, is approximately $4.8 \times 10^{4}$. The velocity scale $\lambda_{V}$ is assumed $1 / 3$ for typical strong wind events, which yields a time scale $\lambda_{T}$ of approximately $1 / 33$. The wind direction $\theta$ is varied from 0 to $90^{\circ}$ for gable and troughed roofs and 0 to $180^{\circ}$ for mono-sloped roofs at a step of $15^{\circ}$ (Fig. 3). The outputs of the force balance are sampled simultaneously at a rate of $200 \mathrm{~Hz}$ for a period of $19 \mathrm{~s}$, which corresponds to $10 \mathrm{~min}$ in full scale. The measurements are repeated six times under the same condition. The statistics of the aerodynamic force and moment coefficients are evaluated by applying ensemble average to the results of these six consecutive runs. The drag forces on the four supporting legs are measured separately and are subtracted from the overall loads to produce loads on roof alone.

\section{Table 2 Characteristics of the shade cloth fabrics.}

\begin{tabular}{llll}
\hline Fabric & Thickness $(\mathrm{mm})$ & Unit weight $\left(\mathrm{N} / \mathrm{m}^{2}\right)$ & $K$ \\
\hline A & 0.70 & 2.61 & 9.2 \\
B & 0.72 & 2.71 & 9.4 \\
C & 1.60 & $3.12-3.43$ & 45 \\
D & 1.03 & 5.88 & 14 \\
\hline
\end{tabular}

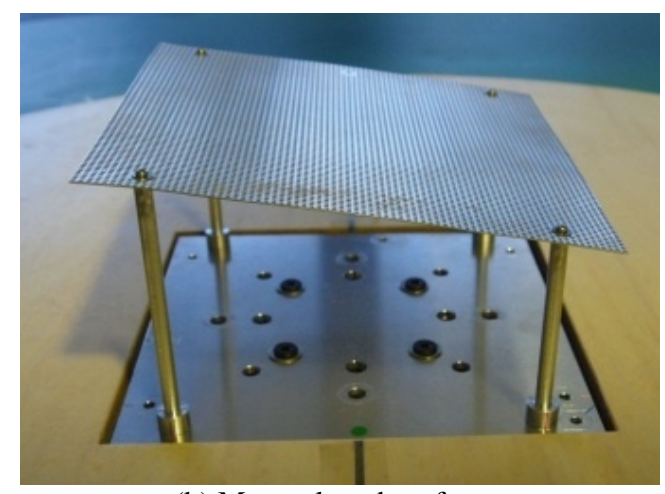

(b) Mono-sloped roof

Fig. 2 Wind tunnel models $\left(\beta=\mathbf{1 0}^{\circ}\right)$. 


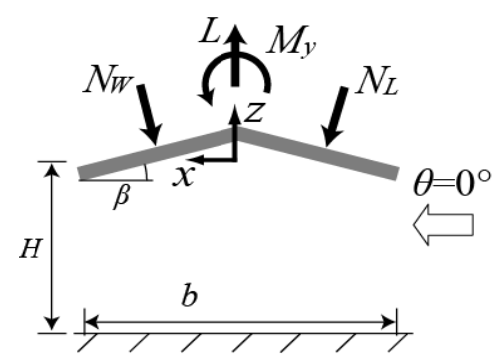

(a) Side view

Fig. 3 Notation and coordinate system (gable roof).

\section{Comparison with the Previous Studies}

Fig. 4 shows a comparison between the present and previous results for $C_{L}$ and $C_{M y}$ on a solid gable roof with $\beta=10^{\circ}$. Uematsu et al. [4] obtained these values from a simultaneous pressure measurement at many points on the top and bottom surfaces of the roof model. A relatively good agreement between these two results can be observed, which indicates that the present experiment is valid.

The values of $C_{L}$ and $C_{M y}$, which are important for discussing the design wind force coefficients, are large in magnitude when $\theta \approx 0^{\circ}$ for gable and troughed roofs and when $\theta \approx 0^{\circ}$ and $180^{\circ}$ for mono-sloped roofs. These wind directions may give some critical conditions for evaluating the design wind force coefficients.

\section{Definition of the Design Wind Force Coefficients}

For the purpose of simplicity, the design wind force coefficients on the roof are specified by two uniformly distributed values $C_{N W}$ and $C_{N L}$ over the windward and leeward halves as shown in Fig. 3. They can be evaluated based on the following procedure, which was used in the previous study on solid canopy roofs $[4,5]$ :

Step 1: The basic values of the wind force coefficients $C_{N W}$ and $C_{N L}$, denoted as $C_{N W 0}$ and $C_{N L 0}$, are determined from a combination of $C_{L}$ and $C_{M y}$ that produces the maximum load effect for winds normal to the ridge $\left(\theta=0^{\circ}\right.$ or $\left.180^{\circ}\right)$. The values of $C_{N W 0}$ and $C_{N L O}$ are calculated as follows:

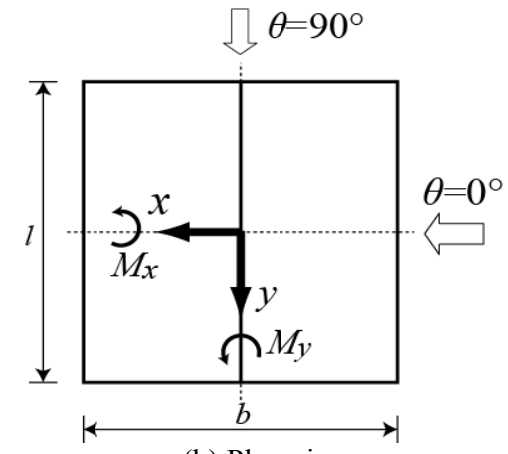

(b) Plan view
$C_{N W 0}=-C_{L}-4 C_{M y}, C_{N L 0}=-C_{L}+4 C_{M y}$

Step 2: In order to consider the effects of $C_{M x}$ and wind direction on the axial forces induced in the columns, a correction factor $\gamma$, which is defined as the ratio of the actual peak force for a wind direction range of $\theta=0-45^{\circ}$ (denoted as "W.D.1") or $\theta=135^{\circ}-180^{\circ}$ (denoted as "W.D.2") to that computed from $C_{N W 0}$ and $C_{N L 0}$ is introduced. It is noted that the authors consider only the "W.D.1" case for the gable and troughed roofs.

Step 3: The design wind force coefficients $C_{N W}{ }^{*}$ and $C_{N L}{ }^{*}$, expressed as equivalent static wind force coefficients, are provided by the following equations:

$$
C_{N W}{ }^{*}=\frac{\gamma C_{N W 0}}{G_{f}}, C_{N L}{ }^{*}=\frac{\gamma C_{N L 0}}{G_{f}}
$$

where, $G_{f}$ represents a gust effect factor, which is determined based on the load effect. Indeed, the gust effect factor is defined by the ratio of the maximum or the minimum axial force to the mean value induced in the columns. Fig. 5 shows the relation between the gust effect factor $G_{f}$ and the mean value of the non-dimensional axial force $N^{*}\left(=N /\left(4 q_{H} b l\right)\right)$ obtained under various conditions. When the value of $\mid N^{*}$ mean $\mid$ is small, $G_{f}$ exhibits a large value. However, as $\mid N^{*}$ mean $\mid$ increases, the $G_{f}$ values collapse into a narrow range around $G_{f}=2.0$. Since focus should be on larger values of $N^{*}$ from the viewpoint of structural design, the value of $G_{f}=2.0$ is used for evaluating $C_{N W}{ }^{*}$ and $C_{N L}{ }^{*}$ in the following discussion.

The most important problem for specifying the design wind force coefficients is how to combine the values of $C_{L}$ and $C_{M y}$ in Eq. (4). The wind force 


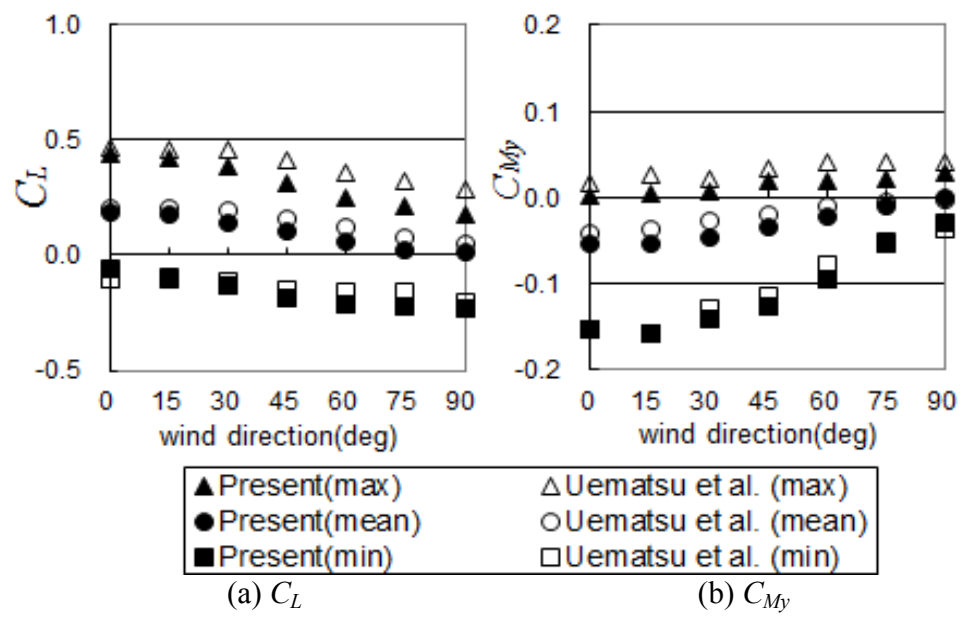

Fig. 4 Comparison with the previous results for solid roofs.

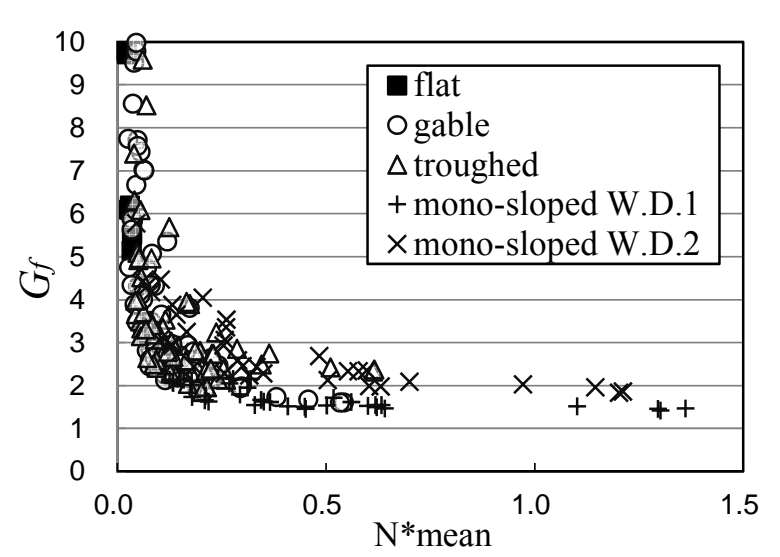

Fig. 5 Gust effect factor $G_{f}$ based on the axial forces induced in the columns.

coefficients should be determined so that they produce the maximum load effect.

Fig. 6 shows a phase-plane representation of the $C_{M y}-C_{L}$ relation for a gable roof with $\beta=5^{\circ}$ when $\theta=0^{\circ}$. There exists a positive correlation between these two values. The correlation becomes poorer as the porosity increases. The previous study on solid canopy roofs [4] indicated that the correlation also became poorer with increasing $\beta$. Similar feature was observed for the porous canopy roofs tested in the present study. The envelop of the $C_{M y}-C_{L}$ trajectory is approximated by a hexagon shown in Fig. 7. The critical condition producing the maximum load effect may be given by one of the apexes of the hexagon. In order to investigate the load combination effects, the axial forces induced in the columns are computed for the six combinations of $C_{L}$ and $C_{M y}$ (Points 1-6) in Fig. 7, assuming that the roof is rigid and supported by the four corner columns. Focus is on the two load cases A and $\mathrm{B}$, producing the maximum tension and compression in the columns, respectively. Substituting the corresponding $C_{L}$ and $C_{M y}$ values into Eq. (4), the authors obtain the values of $C_{N W 0}$ and $C_{N L 0}$ for each load case.

The correction factor $\gamma$ in Eq. (5) is obtained from the ratio of the actual maximum or minimum axial force for the above-mentioned wind direction range (W.D.1 or W.D.2) to the predicted value from the $C_{N W 0}$ and $C_{N L 0}$ values.

\section{Wind Force Coefficients for Porous Canopy Roofs}

Figs. 8 and 9 respectively show the results on $C_{N W}{ }^{*}$ and $C_{N L}{ }^{*}$ for gable and troughed roofs, plotted as a function of porosity $p$. It can be seen that the wind force coefficients generally decrease in magnitude with an increase in $p$. Then, the ratios $R$ of the $C_{N W}{ }^{*}$ and $C_{N L}{ }^{*}$ values for the porous canopy roofs to those for the corresponding solid roofs are computed. The results for gable roofs are shown in Fig. 10. It is noted that the data are not plotted for the cases where the $C_{N W}{ }^{*}$ and $C_{N L}{ }^{*}$ values for solid roofs are very small, because such a case provides unrealistic values of $R$. These results indicate that the ratio $R$ generally decreases with 


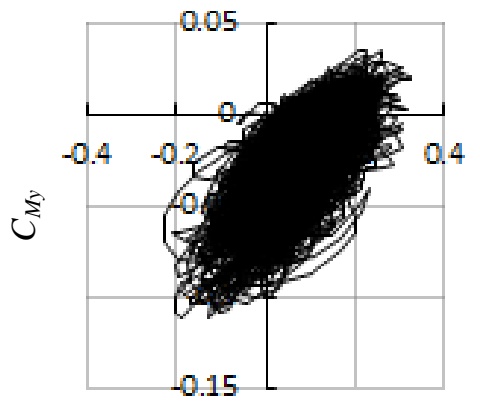

$C_{L}$

(a) $p=0$ (solid)

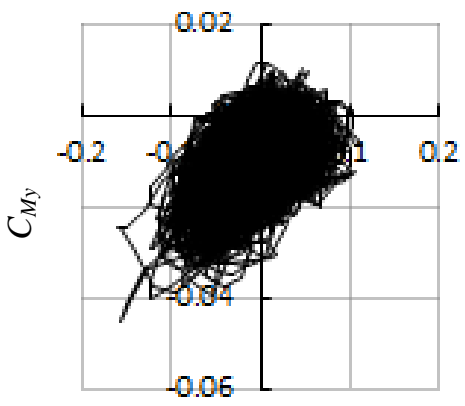

$C_{L}$

(b) $p=0.20$ (porous)

Fig. 6 Phase-plane representation of the $C_{M y}-C_{L}$ relation for a gable roof with $\beta=5^{0}\left(\theta=0^{\circ}\right)$.

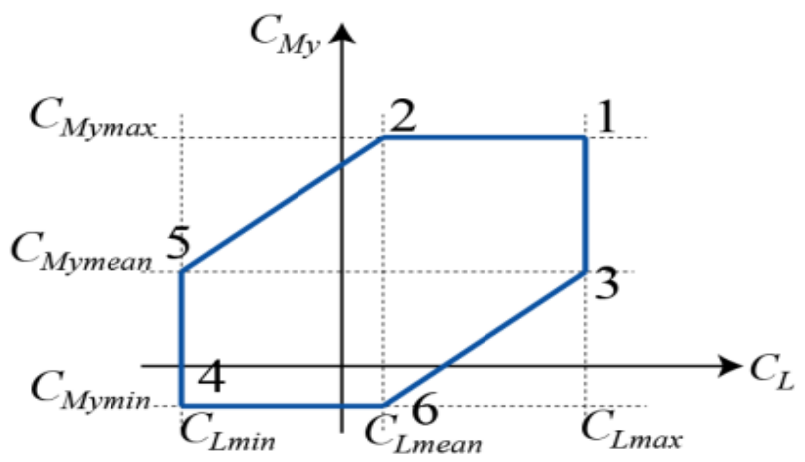

Fig. 7 A model of the envelope of the $C_{M y^{-}} C_{L}$ trajectory.
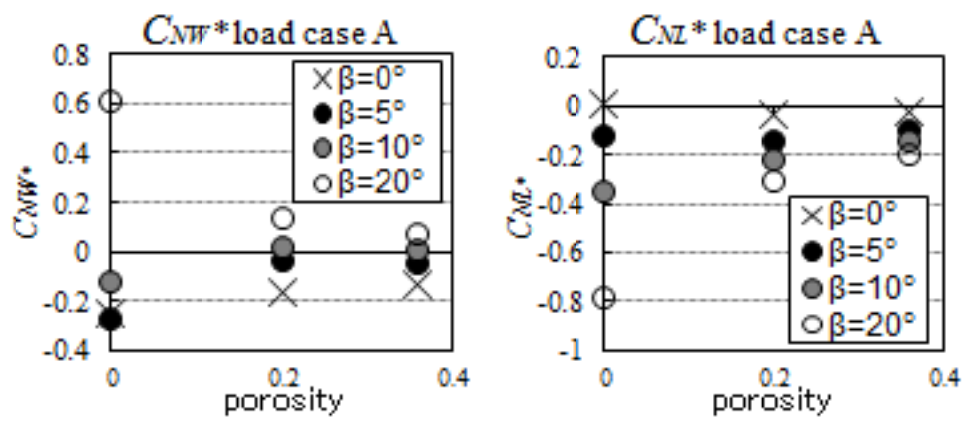

(a) Load case A
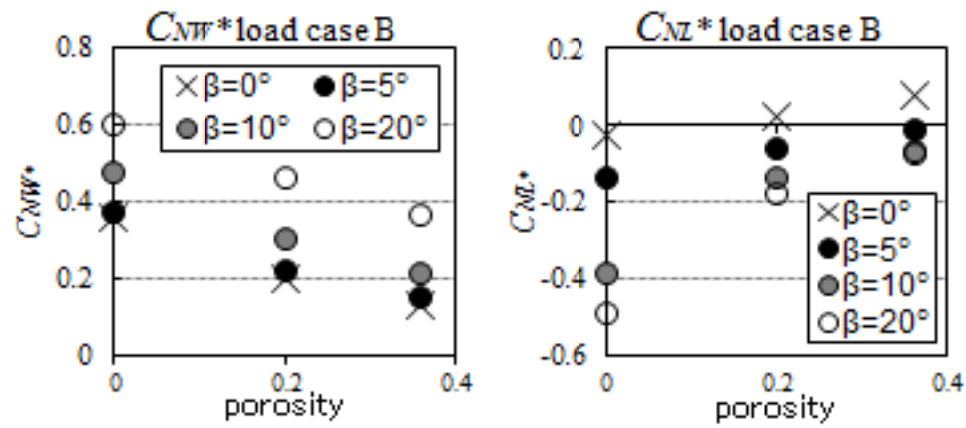

(b) Load case B

Fig. 8 Wind force coefficients for gable roofs (W.D.1). 

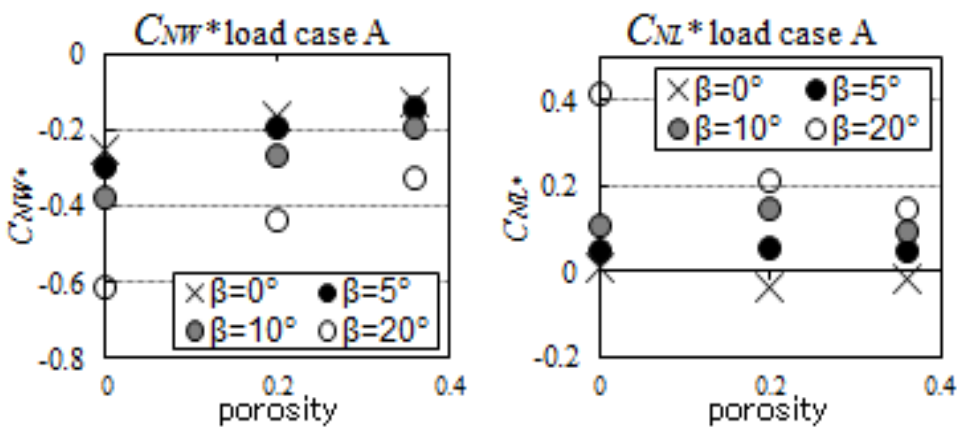

(a) Load case A
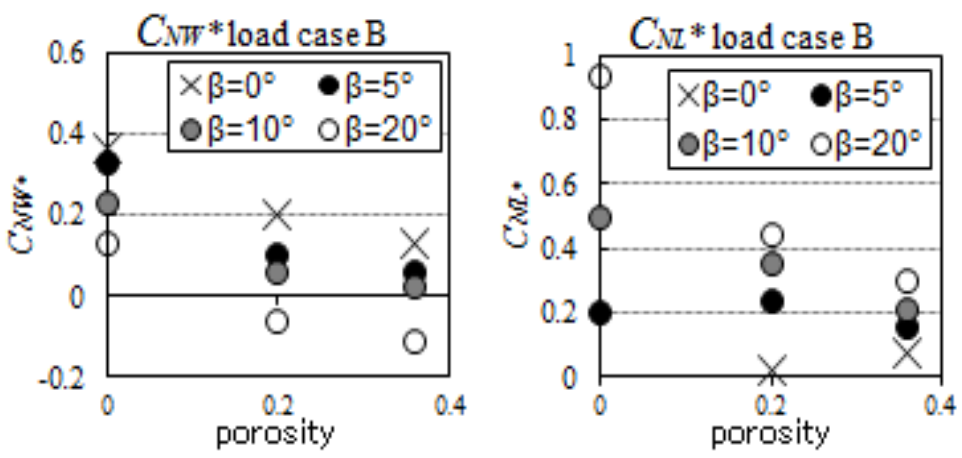

(b) Load case B

Fig. 9 Wind force coefficients for troughed roofs (W.D.1).
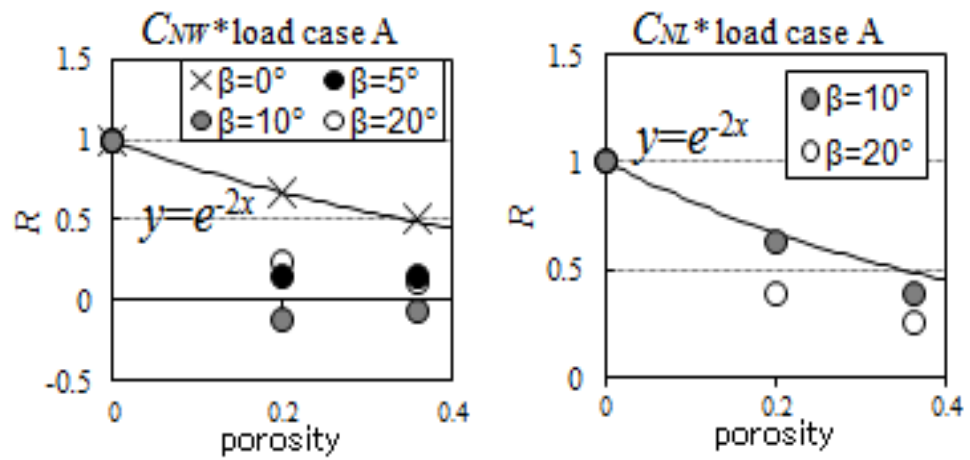

(a) Load case A
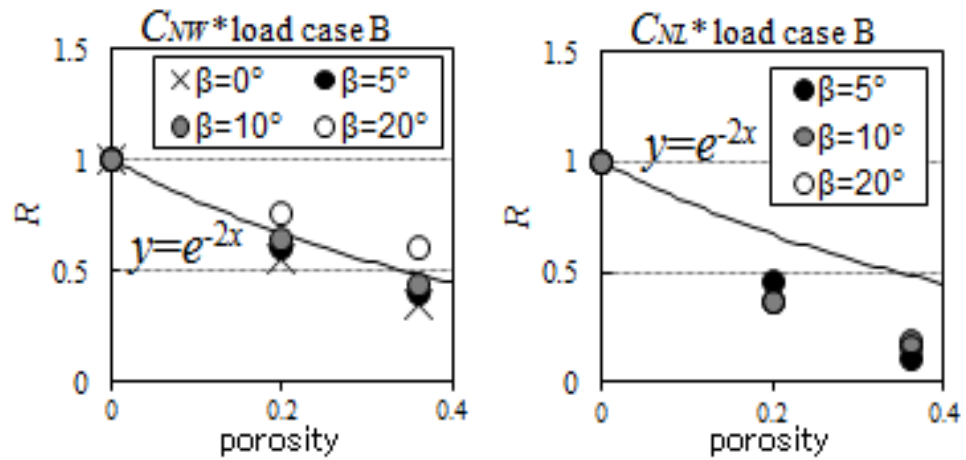

(b) Load case B

Fig. 10 Reduction factor $\boldsymbol{R}$ of wind force coefficients for gable roofs (W.D.1). 


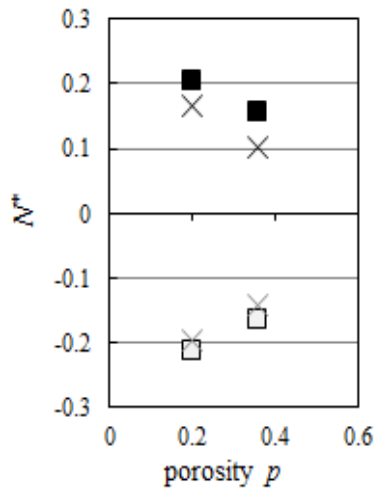

(a) $\beta=10^{\circ}$

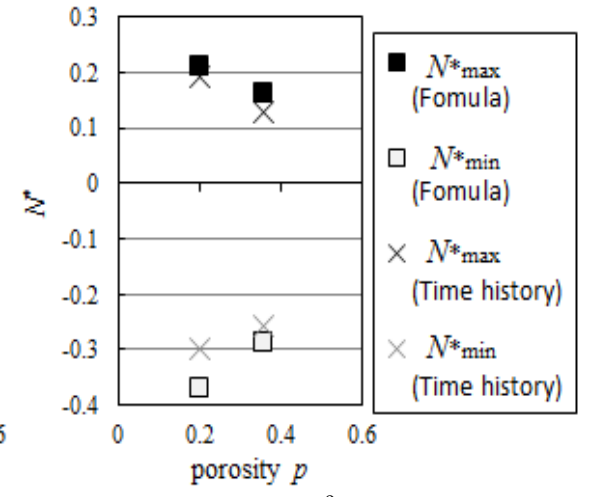

(b) $\beta=20^{\circ}$

Fig. 11 Non-dimensional axial forces induced in the columns for gable roofs (W.D.1).

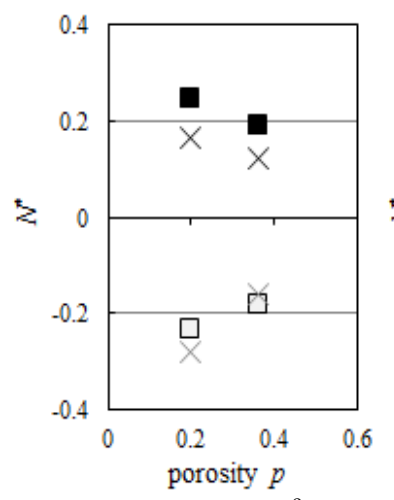

(a) $\beta=10^{\circ}$

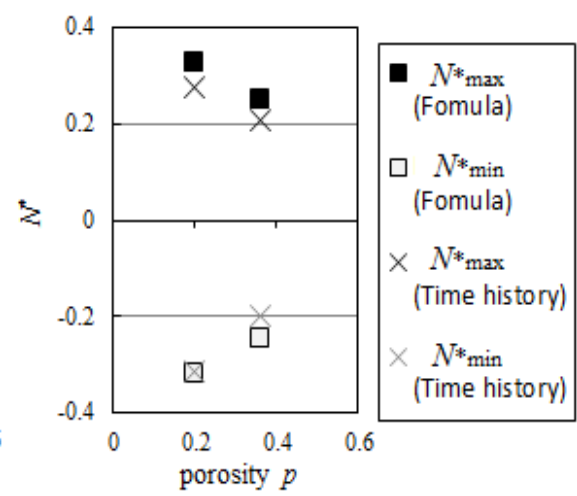

(b) $\beta=20^{\circ}$

Fig. 12 Non-dimensional axial forces induced in the columns for troughed roofs (W.D.1).

increasing $p$. It is found that the effect of roof pitch $\beta$ on $R$ is relatively small. The envelop of the results for various cases can be given by the following equation:

$$
R=e^{-2.0 p}
$$

That is, the wind force coefficients $C_{N W}{ }^{*}$ and $C_{N L}{ }^{*}$ for porous roofs can be given by the product of $R$ and the values for solid roofs. Substituting Eq. (2) into Eq. (6), the authors obtain $R$ from a given value of $K$ (a given shade cloth fabric). Then, the authors can calculate $C_{N W}{ }^{*}$ and $C_{N L}{ }^{*}$ for the porous canopy roof.

The validity of the wind force coefficients obtained above is investigated from the viewpoint of load effect. The maximum tension and compression induced in the columns are obtained from a time-history analysis and compared with the predicted values from the $C_{N W}{ }^{*}$ and $C_{N L}{ }^{*}$ models together with the gust effect factor $\left(G_{f}=\right.$ 2.0). The results for gable and troughed roofs are shown in Figs. 11 and 12, respectively. The predicted values are nearly equal to or somewhat larger than those obtained from the time-history analysis. That is, Eq. (6) can be used for evaluating the wind force coefficients on porous canopy roofs, together with those for solid roofs presented by Uematsu et al. [5].

\section{Conclusions}

The wind force coefficients for designing the structural frames of porous canopy roofs were proposed, based on a series of wind tunnel experiments with rigid porous roof models made of perforated thin duralumin plates. First, an empirical formula representing the relation between the pressure loss coefficient $K$ and porosity $p$ of the perforated plates was provided. Next, the overall aerodynamic forces and moments acting on three kinds of roofs (i.e., gable, troughed and mono-sloped roofs) were measured with a six-component force balance. Based on the results, the design wind force coefficients were discussed from the viewpoint of load effect. In the present study, the 
axial forces induced in the columns were regarded as the load effects for discussing the design wind loads, assuming that the roof was supported by the four corner columns. The design wind force coefficients, represented as uniformly distributed values on the windward and leeward halves of the roof, were provided as a function of the roof pitch and porosity for each of the three roof shapes. The effect of porosity was represented as a reduction factor on the wind force coefficients for solid roofs. The application of the proposed formula was verified based on a comparison between the maximum load effects obtained from the formula with those obtained from the dynamic analysis using the time history of aerodynamic force and moment coefficients.

\section{Acknowledgments}

A part of the present study is financially supported by Nohmura Foundation for Membrane Structure's Technology.

\section{References}

[1] S.J. Gumley, A parametric study of extreme pressures for the static design of canopy structures, Journal of Wind Engineering and Industrial Aerodynamics 16
(1984) 43-56.

[2] C.W. Letchford, J.D. Ginger, Wind loads on planar canopy roofs, Part 1: Mean pressure distributions, Journal of Wind Engineering and Industrial Aerodynamics 45 (1992) 25-45.

[3] J.D. Ginger, C.W. Letchford, Wind loads on planar canopy roofs, Part 2: Fluctuating pressure distributions and correlations, Journal of Wind Engineering and Industrial Aerodynamics 51 (1994) 353-370.

[4] Y. Uematsu, E. Iizumi, T. Stathopoulos, Wind force coefficients for designing free-standing canopy roofs, Journal of Wind Engineering and Industrial Aerodynamics 95 (2007) 1486-1510.

[5] Y. Uematsu, E. Iizumi, T. Stathopoulos, Wind force coefficients for the structural frames of free-standing canopy roofs, in: Proceedings of the 12th International Conference on Wind Engineering, Cairns, Australia, July 1-6, 2007, pp. 455-462.

[6] C.W. Lechford, A. Row, A. Vitale, J. Wolbers, Mean wind loads on porous canopy roofs, Journal of Wind Engineering and Industrial Aerodynamics 84 (2000) 197-213.

[7] Y. Uematsu, H. Sakurai, Y. Miyamoto, E. Gavansky, Wind Force Coefficients for Designing Porous Free-Standing Canopy Roofs, Research, Development, and Practice in Structural Engineering and Construction, Research Publishing Services, 2012, pp. 613-618.

[8] T. Aihara, H. Terazaki, Influence of permeable outer skin on wind pressure acting on building wall measured in wind-tunnel test, in: Proceedings of the 22nd National Symposium on Wind Engineering, Tokyo, Japan, Dec. 5-7, 2012, pp. 299-304. (in Japanese) 